\title{
HETERONORMATIVIDADE E ENSINO NA EDUCAÇÃO BÁSICA: UM ESTADO DO CONHECIMENTO
}

\author{
Katamara Medeiros Tavares Melo \\ Universidade do Estado do Rio Grande do Norte (UERN), Natal, Rio \\ Grande do Norte, Brasil \\ Francisco das Chagas SiLVA SOUZA \\ Instituto Federal de Educação, Ciência e Tecnologia do Rio Grande do \\ Norte (IFRN), Mossoró, Rio Grande do Norte, Brasil \\ Verônica Maria de Araújo Pontes \\ Universidade do Estado do Rio Grande do Norte (UERN), Natal, Rio \\ Grande do Norte, Brasil
}

\begin{abstract}
Resumo: Neste estudo descritivo e qualitativo, analisamos dezesseis trabalhos do Banco de teses e dissertações da CAPES, acessiveis na Plataforma Sucupira, que atendiam a temática da heteronormatividade na educação básica. No Brasil, concentra-se o maior número de crimes de homotransfobia do mundo. A superação desta realidade aponta para o respeito à diversidade de gênero, ainda frágil nas práticas de ensino, principalmente na educação infantil. Mesmo com a supressão dos temas transversais sobre diversidade sexual no currículo, acreditamos que retrocessos e avanços são inerentes à dinâmica das relações de ensino e aprendizado, tendo como resultado o inédito respeito e emancipação da diversidade de gênero.
\end{abstract}

Palavras-chave: Heteronormatividade. Gênero. Educação básica. Diversidade sexual.

\section{INTRODUÇÃO}

Com base em dados publicados pelo Grupo Gay da Bahia (GGB), Ayer e Bottrel (2017), em reportagem no jornal Estado de Minas, alertam para o fato de o Brasil ser considerado o país com maior número de mortes violentas entre pessoas travestis, transgêneras e homoafetivas. Segundo a matéria, o ano de 2016 apresentou 347 casos de assassinatos à população LGBT (lésbicas, gays, bissexuais e transexuais), o maior número desde o início da pesquisa desenvolvida pelo GGB, há 37 anos.

Os crimes se enquadram em homofobia. As travestis, as pessoas transgêneras e os gays são as vítimas em evidência mais vulneráveis aos crimes violentos, com caracteres de crueldade, principalmente aos transgêneros, que apresentam características 
femininas. Para Karnal (2017), é provável que a misoginia tenha dado origem à homofobia, que se fortalece pelos ditos da matriz heteronormativa.

Do nascimento à morte, os corpos obedecem e encenam para fora de si, pensamentos, comportamentos e atitudes conforme foram programados e educados no sistema (LOURO, 2000). Inicialmente na família, e, continuando na escola, reitera-se a manutenção dos papéis "naturais" para o homem e a mulher, pelos discursos e práticas impeditivos, omissos e imutáveis. Assim, as pessoas não heterossexuais são socialmente invisíveis, hostilizadas e não respeitadas (BUTLER, 2015).

Consideramos a necessidade de se analisar o contexto e entender as origens e reiterações que fazem da heteronormatividade discurso e prática. Como a escola é um espaço em que a sociedade se reproduz (embora seja também responsável por mudanças substanciais nessa mesma sociedade), o nosso objetivo, neste artigo, é mapear as pesquisas produzidas sobre a heteronormatividade na educação básica, configurando-se como um estado do conhecimento, cujo percurso metodológico será explicitado adiante.

Para a construção desse estudo, consultamos as investigações acadêmicas disponibilizadas no Banco de Teses e Dissertações da Coordenação de Aperfeiçoamento Comissão de Pessoal do Nível Superior (CAPES). Analisamos 16 produções que têm como tema de investigação a heteronormatividade na educação básica (considerando o espaço escolar e as políticas de ensino). Restringimo-nos aos trabalhos que estavam disponíveis para download na Plataforma Sucupira.

Para a nossa análise, pautamo-nos em uma abordagem teórica acerca do tema heteronormatividade a partir dos escritos de Beauvoir (2016), Bourdieu (2002), Butler (2015), Foucault (1982), Louro (2000, 2009, 2016), Scott (1989), entre outros.

$\mathrm{O}$ artigo está dividido em duas partes. Na primeira, realizamos, ainda que de forma breve, uma discussão teórica desenvolvida por alguns autores clássicos na temática de gênero. Em seguida, apresentamos os resultados de nossa pesquisa baseados no Banco de Teses e Dissertações da Capes.

\section{HETERONORMATIVIDADE: CONSIDERAÇÕES INICIAIS}

A heteronormatividade, mesmo em face às coerções para sua manutenção, provoca também questionamentos e subversão, culminando em sua própria desestabilização e superação, conforme alerta Butler (2015).

Embora a escola se configure como espaço de diversidades, Carrara (2009) argumenta que a matriz heteronormativa, presente na escola, sustenta a homofobia. Para o questionamento, enfrentamento e superação desta realidade, além de medidas políticas e jurídicas, é necessária a abordagem dos estudos de gênero nas práticas de ensino, uma vez que este emancipa as pessoas (LOURO, 2016).

Destarte, percebemos que os espaços escolares e os seus atores são elementos essenciais nesse processo de superação. A iminência de novos saberes, atitudes e fazeres são as principais estratégias para entender e respeitar as diversidades.

Beauvoir (2016) apontou a tensão entre os privilégios de gênero masculino e a submissão do gênero feminino. De fato, ao longo da história, homens e mulheres estabeleceram relações desiguais de poder. Para a autora, a cultura que ditou ao homem 
o papel de macho - ser forte, desapegado aos sentimentos afetivos e se apropriar do contexto - relegou à mulher a manutenção e equilíbrio do lar, sendo destinado ao homem usufruir de sua subserviência.

Scott (1989) criticou a compreensão de gênero limitada ao binarismo mulher versus homem dentro da matriz heterossexual, alertando para a invisibilidade das diversidades sexuais existentes. Para a autora, o conceito de gênero situa e analisa as relações sociais estabelecidas entre os sexos. Portanto, torna-se uma categoria social imposta a um corpo sexuado.

Buscamos em Nogueira, Aquino e Cabral (2017) a abordagem dos termos cisgênero e transgênero para entender as diversidades de gênero. Para as pessoas cisgênero, a identidade de gênero corresponde ao sexo biológico, bem como aos papéis designados pela cultura. Assim, uma pessoa de sexo feminino (por que nasceu com uma vagina) deve se entender "mulher" e deve assumir a feminilidade que lhe foi designada. De forma oposta, mas similar: o homem também deve assumir o papel condizente para ele, segundo a sua cultura. Portanto, mulher e homem são coagidos, culturalmente, a exercer as obrigações de gênero que lhes foram instituídas desde o nascimento.

Subvertendo a ordem da identidade de gênero designada ao sexo biológico, constam as pessoas transgêneras. Seus comportamentos, identidades, predileções e desejos não se articulam ao esperado para o seu sexo. Assim, seu gênero (ser masculino, ser feminino, ser masculino/feminino, ou não se enquadrar em nenhuma das alternativas impostas) não se vincula ao seu sexo biológico.

Assumir um papel de gênero não implica efetivamente na orientação sexual da pessoa. Há indivíduos cisgêneros que desejam pessoas de sexo biológico semelhante ao seu. Dessa forma, uma pessoa que nasceu com pênis poderá se identificar masculino (cisgênero) e desejar uma mulher - na condição de heterossexual. Se desejar um homem, a pessoa se reconhece na homoafetividade. Caso se sinta atraído pelos dois gêneros, instala-se na bissexualidade. Portanto, conforme Louro (2016), existem diversas orientações sexuais que escapam aos conceitos.

Para Louro (2009), o alinhamento coagido entre sexo-gênero-sexualidade sustenta a heteronormatividade, que é a produção e reiteração compulsória da norma heterossexual. Uma relação simbiótica de manutenção da ordem simbólica dos papéis sexuais. Nogueira, Aquino e Cabral (2017) destacam que os enunciados da heterossexualidade compulsória estabelecem padrões de sentimentos e comportamentos femininos e masculinos - as normas de gênero.

Louro (2009) afirma que os indivíduos que subvertem essas normas ficam à margem das preocupações da escola, da justiça ou da sociedade em geral. Paradoxalmente, os "marginalizados" continuam necessários, pois servem de parâmetros para os contornos daqueles tidos como "normais". Para a autora, a lógica é binária e a ideia de multiplicidade escapa da compreensão humana. Segundo Butler $(2015$, p. 44):

[...] A matriz cultural por meio da qual a identidade de gênero se torna inteligível exige que certos tipos de identidades não possam existir - isto é, aqueles em que o gênero não decorre do sexo e aqueles em que as práticas do desejo não decorrem nem do sexo, nem do gênero.

Assim, os enfoques sobre gênero e diversidade sexual transcendem conteúdos limitados à mulher da matriz heterossexual, vislumbrando outros gêneros não alinhados 
ao biologicismo. Esta complexidade do conceito de gênero "[...] exige um conjunto interdisciplinar e pós-disciplinar de discursos, com vistas de resistir à domesticação acadêmica dos estudos sobre gênero ou dos estudos sobre mulheres e a de radicalizar a noção de crítica feminista" (BUTLER, 2015, p. 13).

Estabelecendo relação com as leituras em Morin (2003), em nosso corpo há campos disciplinares que se interceptam e se precisam mesmo diante das diferenças existentes entre as formas e funções desempenhadas pelos diferentes órgãos e sistemas. Esse corpo interage com outros corpos que se interrelacionam com o mundo.

Ainda que em meio a tantas diversidades, a sexualidade sofre as interdições e as coerções das normas que padronizam as condutas heterossexuais. Para isto, usa-se o argumento da naturalização do que é biológico. Na realidade, valem-se das tradições culturais para manter os ideais de ordem através das normas (BUTLER, 2015).

Entendemos que a construção da masculinidade e feminilidade, circunscritas na matriz heterossexual, disfarçam, na noção de complementaridade, a opressão existente do feminino pelo masculino. Por isso, a reprodução da norma heterosexista funciona também a serviço da dominação masculina. Ambos se retroalimentam para se manterem (BOURDIEU, 2002).

Tal qual a lógica da relação entre opressor e oprimido, tratada por Freire (2015), comparamos a situação da construção de masculinidade instituída na matriz heterossexual. Bourdieu (2002) defende que, no homem, o peso de ser dominador, constitui-se uma cilada ao próprio universo masculino.

Ainda sobre as iniquidades em gênero, Butler (2015) destaca que essas assimetrias fazem perder o aprofundamento de quaisquer outras identidades e comportamentos que subvertam a ordem estabelecida. Trata-se de projetar, também, a existência das identidades e relações transgêneras. É relevante, pois, visibilizar os sujeitos subversivos.

Para Junqueira (2009) é necessário o envolvimento da comunidade escolar para a desestabilização da homofobia. Essa ênfase também é citada incessantemente por Louro (2016) à proposição de um currículo Queer, que na língua inglesa significa estranho, fora do comum, não limitado aos padrões da normalidade convencional. Ou seja, aquele que se desprende de um espaço projetado, embora esteja em sintonia com os anseios do real.

A teoria Queer tem em Judith Butler seu marco conceitual. É apresentada por Louro (2016) como uma terminologia direcionada ao que é estranho, abjeto e sem visibilidade. Por isso, os estudos Queer questionam as designações normativas de identidades de gênero e orientações sexuais, uma vez que estas estão em fluidez constante, tal qual todas as metamorfoses que constituem a vida e os saberes.

Baseado nos pesquisadores acima destacados, o processo de invisibilidade social das pessoas transgêneras, precisa ser questionado e desestabilizado. A partir disso, entendem a necessária articulação de práticas de ensino que questione a heteronormatização sobre os corpos e culmine com o fortalecimento das práticas de homofobia nas escolas.

Junqueira (2009) observa que não constam documentos oficiais no sistema de dados das escolas a respeito das práticas de homofobia, apontando como determinantes 
desse fato: a omissão permissiva, o preconceito e a naturalização dessa prática como brincadeira sem intenções fatais, principalmente entre adolescentes.

A respeito da percepção dos professores e as manifestações de discriminação, de acordo com dados da Organização das Nações Unidas para a Educação, a Ciência e a Cultura (UNESCO), em 2004,59,7\% dos educadores acham inadmissível a prática de relações homoafetivas e $21,1 \%$ desses docentes não gostariam de ter vizinhos homossexuais. Mesmo que esses números não sejam recentes, não acreditamos que tenha ocorrido muitos avanços na última década, caso levemos em consideração as reportagens e os comentários que ouvimos quase diariamente.

Em 2016, na Rússia, foi divulgado pelas redes sociais o caso de um jovem em Moscou, morto em sala de aula "acidentalmente" durante uma seção de buillyng homofóbico, enquanto a professora apenas observou a ação violenta dos alunos. Posteriormente, a direção da escola classificou o ocorrido como fatalidade e o caso não ganhou a merecida repercussão, em face o país condenar a existência, quiçá manifestações das práticas homoafetivas (MENINO..., 2016).

Cancian (2017), em matéria publicada na Folha de São Paulo, criticou a retirada de menção ao gênero e à orientação sexual do Plano Nacional de Educação (Lei 13.005/2014), com previsão de dez anos de validação. Em nossa compreensão, fundamentada nessa reportagem, esse retrocesso também fortalece a manutenção da heteronormatividade e das práticas de homofobia na escola.

Diante do exposto e motivados pela relevância que tem assumido esse tema no mundo contemporâneo, implicando em revisões curriculares e nas práticas docentes sobretudo na educação básica, haja vista a faixa etária com a qual lidam diariamente, tencionamos conhecer sobre como esse assunto tem sido abordado nas pesquisas em Programas de Pós-Graduação.

\section{A PRODUÇÃO ACADÊMICA SOBRE HETERONORMATIVIDADE NA EDUCAÇÃO BÁSICA}

A pesquisa aqui apresentada é um levantamento da produção acadêmica a respeito de uma temática em evidência contextual, podendo ser enquadrada como um "estado da arte" ou "estado do conhecimento", de acordo com Ferreira (2002).

No entanto, Romanowsky e Ens (2006) esclarecem que há uma diferença entre estado da arte e estado do conhecimento. $O$ primeiro requer estudo que englobe teses, dissertações, periódicos, apresentação temáticas em eventos (congressos), entre outras. O segundo se direciona à abordagem da produção escrita de um setor de publicações específicas sobre a temática em estudo. Portanto, uma vez que este artigo tratará da produção restrita a teses e dissertações disponíveis no repositório da CAPES, será referenciado por nós como um estado do conhecimento.

Recorremos ao Banco de Teses e Dissertações da CAPES, levando em consideração a relevância de pesquisar em um banco de dados legítimo, científico, cuja seriedade é indiscutível do ponto de vista acadêmico.

Para Romanowsky e Ens (2006), estudos desse tipo servem não apenas para identificar as produções acadêmicas acerca de uma determinada temática, mas também para compreender como estas investigações contribuem para o avanço do conhecimento em questão, a sua relevância acadêmica e o impacto sócio-político-cultural que representam. No caso do tema que aqui investigamos, um estado do conhecimento pode 
contribuir para o debate sobre as práticas de ensino na educação básica, apontando novas reflexões, saberes e ações relevantes para a minoração dos danos causados pela cultura heteronormativa na escola.

Pautados em tal interesse, iniciamos a busca no Portal de Teses e Dissertações da Capes a partir do termo "heteronormatividade". Foram encontrados 189 trabalhos em cinco das Grandes Áreas: Multidisciplinar, Ciências Humanas, Ciências Sociais Aplicadas, Linguística, Letras e Artes. Esse total constituíam-se 47 teses, 136 dissertações de Mestrados Acadêmicos e 6 de Mestrados Profissionais.

Em função do nosso interesse pela discussão sobre a heteronormatividade na educação básica, refinamos a nossa busca assinalando a opção Educação no item Área de Conhecimento. Foram encontrados 44 trabalhos, dos quais 33 eram dissertações e 11 teses. Seriam estes trabalhos que analisaríamos. Entretanto, nem todos estavam disponíveis na Plataforma Sucupira. Isso nos levou a uma nova seleção em torno das publicações disponíveis para download. Nesse caso, seriam as dissertações e teses produzidas entre 2013 e 2016.

Desses 44 trabalhos, verificamos aqueles que enfatizavam a problematização, a desestabilização e a superação da heteronormatividade na educação básica. Embora alguns títulos apresentassem, panoramicamente, essa discussão, ao lermos os resumos, as palavras-chave, a introdução, a metodologia, os resultados e as considerações finais, constatamos que apenas 16 desses trabalhos atendiam aos nossos interesses (13 dissertações e 3 teses). 0 Quadro 1 apresenta as produções eleitas.

QUADRO 1 - Dissertações sobre a problemática da heteronormatividade na educação básica

\begin{tabular}{|c|c|l|c|}
\hline \multirow{2}{*}{ ANO } & AUTORES & \multicolumn{1}{|c|}{ TítULO } & INSTITUIÇÃo \\
\hline \multirow{2}{*}{2013} & CORREA, I.M. & $\begin{array}{l}\text { Gênero e currículo: um movimento de (des) } \\
\text { construção. }\end{array}$ & UERJ \\
\cline { 2 - 5 } & BERTUOL, B. & $\begin{array}{l}\text { Coisas de menino ou de menina? } \\
\text { Pedagogias de gênero nas escolas de } \\
\text { educação infantil. }\end{array}$ & UNILASALLE \\
\hline $\begin{array}{l}\text { DORNELLES, P.G. } \\
\text { práticas pedagógicas da educação física } \\
\text { escolar*. }\end{array}$ & UFRGS \\
\hline
\end{tabular}




\begin{tabular}{|c|c|c|c|}
\hline \multirow{6}{*}{2014} & PICCHETTI, Y.P & $\begin{array}{l}\text { Reiterações e transgressões à } \\
\text { heteronormatividade na escola em tempos } \\
\text { de educação para diversidade }\end{array}$ & UFRGS \\
\hline & SANTANA, H. S. & $\begin{array}{l}\text { Questões de gênero e sexualidade no } \\
\text { currículo escolar. }\end{array}$ & UERJ \\
\hline & CRUZ, T. A. & $\begin{array}{l}\text { Diferença em disputa: os embates acerca do } \\
\text { kit anti-homofobia (2004-2012). }\end{array}$ & UERJ \\
\hline & ELIAN, I. T. & $\begin{array}{l}\text { Memórias escolares dos sujeitos LGBTT: a } \\
\text { escola como mediadora das identidades } \\
\text { sexuais e de gênero. }\end{array}$ & UEMG \\
\hline & ALMEIDA, H.S.S & $\begin{array}{l}\text { Professoras trans } \quad \text { brasileiras: } \\
\text { ressignificações de gênero e de } \\
\text { sexualidades no contexto escolar*. }\end{array}$ & UFU \\
\hline & PRADO, V.M. do & $\begin{array}{l}\text { Entre ditos e não ditos: a marcação social de } \\
\text { diferenças de gênero e sexualidade por } \\
\text { intermédio das práticas escolares de } \\
\text { educação física*. }\end{array}$ & UNESP \\
\hline \multirow{2}{*}{2015} & PUCHALSKY, H. & $\begin{array}{l}\text { A/R/Tografia e enunciações queer: } \\
\text { hibridizações entre arte, gênero e } \\
\text { sexualidade nas narrativas de professores } \\
\text { de arte. }\end{array}$ & UFPR \\
\hline & CESPEDES, C. R. & $\begin{array}{l}\text { Memórias de infância, relações de gênero e } \\
\text { sexualidade nos significados e narrativas de } \\
\text { professores/as Rondonópolis - MT }\end{array}$ & UFMT \\
\hline \multirow{5}{*}{2016} & $\begin{array}{l}\text { RODRIGUES, T. } \\
\text { A. }\end{array}$ & $\begin{array}{l}\text { Morrer para nascer } \quad \text { Travesti: } \\
\text { performatividades, escolaridades e a } \\
\text { pedagogia da intolerância. }\end{array}$ & UFSCar \\
\hline & LARA, R. B. & $\begin{array}{l}\text { O que dizem os (as) Docentes acerca da } \\
\text { Diversidade Sexual na Escola. }\end{array}$ & UFOP \\
\hline & MARTINS, L. R. & $\begin{array}{l}\text { Entre ocós, truques e atraques: a produção } \\
\text { de confetos sobre as experiências de } \\
\text { educadoras trans do projeto "trans"forma } \\
\text { ação. }\end{array}$ & FUFPI \\
\hline & LIMA, V. B. C de. & $\begin{array}{l}\text { Mentir para si mesmo é sempre a pior } \\
\text { mentira: a heteronormatividade na } \\
\text { narrativa da trajetória escolar de mulheres } \\
\text { lésbicas e bissexuais. }\end{array}$ & UERJ \\
\hline & OLIVEIRA, A. L. & $\begin{array}{l}\text { Discursos sobre corpo, gênero e } \\
\text { sexualidade na educação do colégio de } \\
\text { aplicação da Universidade Federal de } \\
\text { Sergipe. }\end{array}$ & UFSE \\
\hline
\end{tabular}

* Teses.

FONTE: Quadro elaborado pelos autores a partir do Banco de Teses e Dissertações da CAPES, no período de 2013 a 2016.

Tomando como referência as observações de Romanowsky e Ens (2006), ao ressaltarem a importância de se fazer comparações entre regiões para identificar 
tendências comuns, assim como especificidades e problemas políticos e ideológicos, observamos que a produção significativa dos trabalhos, nessa temática, está nas regiões Sudeste e Sul. Entre os anos 2013 e 2016 foram produzidas uma tese e três dissertações na região Sul, duas teses e sete dissertações no Sudeste, duas dissertações no Nordeste e uma dissertação no Centro-Oeste. Na região Norte, não identificamos trabalhos com esse tema (Gráfico 1).

GRÁFICO 1 - Quantitativo da produção acadêmica sobre heteronormatividade na educação básica

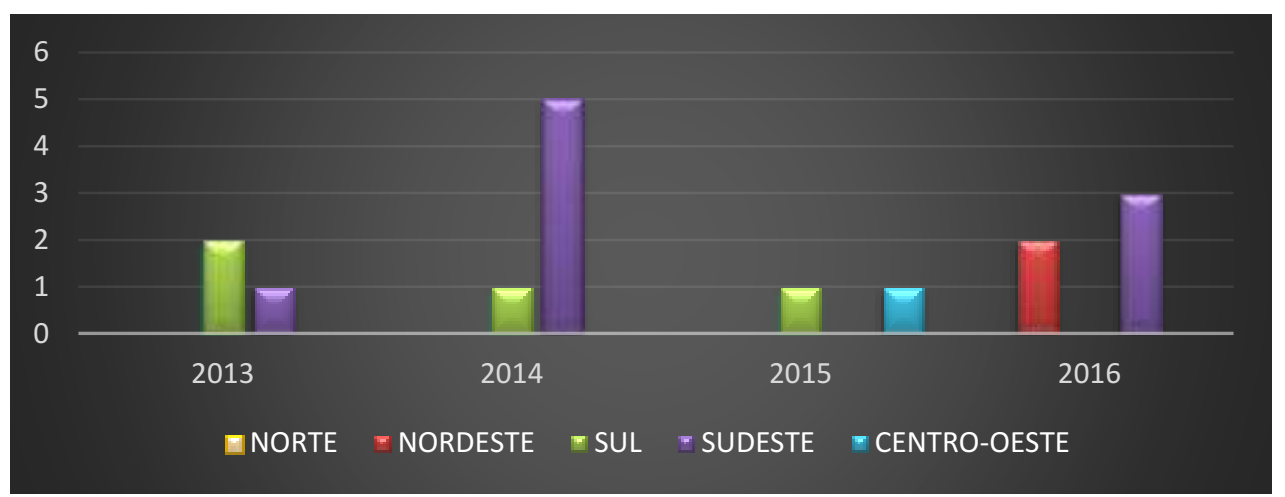

FONTE: Gráfico elaborado pelos autores a partir do Banco de Teses e Dissertações da CAPES.

Merece destacar que no trabalho de Cruz (2014), identificamos o uso da letra " $x$ " nas terminações finais de palavras que designavam os sexos, independente de seus gêneros. Em consonância com Sterling (1993) esta linguagem designa a não pertença aos sexos socialmente construídos. Para Freire,

Mudar a linguagem faz parte do processo de mudar o mundo. A relação linguagem - pensamento - mundo é uma relação dialética, processual e contraditória. [...] a superação de qualquer discurso autoritário, exige ou nos coloca a necessidade de, concomitantemente, com o novo discurso democrático, antidiscriminatório, nos engajarmos em práticas também democráticas (2015, p. 44-45).

Também Picchetti (2014), justifica o uso de artigo "a" para se referir ao número total de gestoras, professoras e alunas da instituição em que desenvolveu a sua pesquisa, composta, em sua maior parte, por pessoas do sexo feminino. Assim, a predominância de mulheres no local da pesquisa explica sua opção de escrita. Nas demais pesquisas não observamos essa peculiaridade.

Com relação aos referenciais teóricos e métodos utilizados nos estudos analisados, o Quadro 2 apresenta uma síntese dos autores mais referenciados e os métodos de coleta e análises dos dados. 
MELO, K. M. T.; SOUZA, F. C. S.; PONTES, V. M. A.

QUADRO 2 - Referências teóricas e métodos utilizados nas teses e dissertações sobre a problemática da heteronormatividade na educação básica

\begin{tabular}{|c|c|c|c|}
\hline ANO & AUTORES/ TÍTULO/LOCAL & $\begin{array}{l}\text { REFERENCIAL } \\
\text { TEÓRICO }\end{array}$ & MÉTODO \\
\hline \multirow{3}{*}{2013} & $\begin{array}{l}\text { CORREA, I.M. Gênero e currículo: } \\
\text { um movimento de (des) } \\
\text { construção (UERJ). }\end{array}$ & $\begin{array}{l}\text { BUTLER, J. } \\
\text { LOURO, G.L. } \\
\text { MACÊDO, E. }\end{array}$ & $\begin{array}{l}\text { Entrevistas } \\
\text { semiestruturadas com doze } \\
\text { professoras e gestores do } \\
\text { ensino fundamental ( } 8^{\circ} \text { e } 9^{\circ} \\
\text { anos), na cidade do Rio de } \\
\text { Janeiro. }\end{array}$ \\
\hline & $\begin{array}{l}\text { BERTUOL, B. Coisas de menino } \\
\text { ou de menina? Pedagogias de } \\
\text { gênero nas escolas de educação } \\
\text { infantil (UNILASALLE). }\end{array}$ & $\begin{array}{l}\text { BUGES, M. I. E. } \\
\text { BUTLER, J. } \\
\text { FELIPE, J. } \\
\text { FOUCAULT, M. } \\
\text { HALL, S. } \\
\text { LOURO, G. L. }\end{array}$ & $\begin{array}{l}\text { Diário de campo e grupo } \\
\text { focal com professores em } \\
\text { seis escolas de Educação } \\
\text { Infantil em um Município } \\
\text { de Serra Gaúcha. }\end{array}$ \\
\hline & $\begin{array}{l}\text { DORNELLES, P.G. A (Hetero) } \\
\text { Normalização dos corpos em } \\
\text { práticas pedagógicas da } \\
\text { educação física escolar } \\
\text { (UFRGS)*. }\end{array}$ & $\begin{array}{l}\text { BUTLER, J. } \\
\text { FOUCAULT, M. } \\
\text { LOURO, G. L. }\end{array}$ & $\begin{array}{l}\text { Análise } \\
\text { curricular e documental } \\
\text { políticos projetos } \\
\text { questionários, entrevistas e } \\
\text { grupo focal. }\end{array}$ \\
\hline
\end{tabular}




\begin{tabular}{|c|c|c|c|}
\hline \multirow{5}{*}{2014} & $\begin{array}{l}\text { PICCHETTI, Y. P. Reiterações e } \\
\text { transgressões à } \\
\text { heteronormatividade na escola } \\
\text { em tempos de educação para } \\
\text { diversidade (UFRGS). }\end{array}$ & $\begin{array}{l}\text { BUTLER, J. } \\
\text { FOUCAULT, M. } \\
\text { LOURO, G. L. }\end{array}$ & Estratégias etnográficas. \\
\hline & $\begin{array}{l}\text { SANTANA, H. S. Questões de } \\
\text { gênero e sexualidade no } \\
\text { currículo escolar (UERJ). }\end{array}$ & $\begin{array}{l}\text { BUTLER, J. } \\
\text { FOUCAULT, M. } \\
\text { LOURO, G. L. }\end{array}$ & $\begin{array}{l}\text { Entrevistas com gestores, } \\
\text { professores e alunos da } \\
\text { rede pública do ensino } \\
\text { médio. }\end{array}$ \\
\hline & $\begin{array}{l}\text { CRUZ, T. A. Diferença em } \\
\text { disputa: os embates acerca do } \\
\text { kit anti-homofobia (2004-2012) } \\
\text { UERJ. }\end{array}$ & $\begin{array}{l}\text { BUTLER, J. } \\
\text { FOUCAULT, M. } \\
\text { LOURO, G. L. } \\
\text { MACÊDO, E. }\end{array}$ & $\begin{array}{l}\text { Análise de discurso dos } \\
\text { pronunciamentos nos } \\
\text { plenários da Câmara e no } \\
\text { Senado, no período de } \\
\text { novembro de } 2010 \text { a } \\
\text { outubro de 2012. }\end{array}$ \\
\hline & $\begin{array}{l}\text { ELIAN, I. T. Memórias escolares } \\
\text { dos sujeitos LGBTT: a escola } \\
\text { como mediadora das } \\
\text { identidades sexuais e de gênero } \\
\text { (UEMG). }\end{array}$ & BUTLER, J. & $\begin{array}{l}\text { Narrativas escolares a partir } \\
\text { de entrevistas com lésbicas, } \\
\text { gays, bissexuais, travestis e } \\
\text { transexuais. }\end{array}$ \\
\hline & $\begin{array}{l}\text { ALMEIDA, H. S. S. Professoras } \\
\text { trans brasileiras: ressignificações } \\
\text { de gênero e de sexualidades no } \\
\text { contexto escolar (UFU)*. }\end{array}$ & $\begin{array}{l}\text { BUTLER, J. } \\
\text { FOUCAULT, M. } \\
\text { LOURO, G. L. }\end{array}$ & $\begin{array}{l}\text { Análise de documentos. } \\
\text { Entrevistas e questionários } \\
\text { aplicados para doze (12) } \\
\text { professoras trans das cinco } \\
\text { regiões do país realizadas } \\
\text { no XVII ENTAIDS em } \\
\text { Aracajú no ano de } 2010 \text { e } \\
\text { na edição do mesmo } \\
\text { evento realizada em } 2012 \text {. }\end{array}$ \\
\hline & $\begin{array}{l}\text { PRADO, V.M. do. Entre ditos e } \\
\text { não ditos: a marcação social de } \\
\text { diferenças de gênero e } \\
\text { sexualidade por intermédio das } \\
\text { práticas escolares de educação } \\
\text { física (UNESP)* }\end{array}$ & $\begin{array}{l}\text { BUTLER, J. } \\
\text { FOUCAULT, M. } \\
\text { LOURO, G. L. }\end{array}$ & $\begin{array}{l}\text { Questionários } \\
\text { socioeconômicos. } \\
\text { Elaboração de seis (6) } \\
\text { entrevistas } \\
\text { semiestruturadas com } \\
\text { pessoas homoafetivas, a } \\
\text { partir de suas } \\
\text { rememorações sobre as } \\
\text { aulas de educação física na } \\
\text { Educação Básica. }\end{array}$ \\
\hline & $\begin{array}{l}\text { PICCHETTI, Y. P. Reiterações e } \\
\text { transgressões à } \\
\text { heteronormatividade na escola } \\
\text { em tempos de educação para } \\
\text { diversidade (UFRGS). }\end{array}$ & $\begin{array}{l}\text { BUTLER, J. } \\
\text { FOUCAULT, M. } \\
\text { LOURO, G. L. }\end{array}$ & Estratégias etnográficas. \\
\hline & $\begin{array}{l}\text { SANTANA, H. S. Questões de } \\
\text { gênero e sexualidade no } \\
\text { currículo escolar (UERJ). }\end{array}$ & $\begin{array}{l}\text { BUTLER, J. } \\
\text { FOUCAULT, M. } \\
\text { LOURO, G. L. }\end{array}$ & $\begin{array}{l}\text { Entrevistas com gestores, } \\
\text { professores e alunos da } \\
\text { rede pública do ensino } \\
\text { médio. }\end{array}$ \\
\hline
\end{tabular}


MELO, K. M. T.; SOUZA, F. C. S. PONTES, V. M. A.

\begin{tabular}{|c|c|c|c|}
\hline \multirow[t]{4}{*}{2014} & $\begin{array}{l}\text { CRUZ, T. A. Diferença em } \\
\text { disputa: os embates acerca do } \\
\text { kit anti-homofobia (2004-2012) } \\
\text { UERJ. }\end{array}$ & $\begin{array}{l}\text { BUTLER, J. } \\
\text { FOUCAULT, M. } \\
\text { LOURO, G. L. } \\
\text { MACÊDO, E. }\end{array}$ & $\begin{array}{l}\text { Análise de discurso dos } \\
\text { pronunciamentos nos } \\
\text { plenários da Câmara e no } \\
\text { Senado, no período de } \\
\text { novembro de } 2010 \text { a } \\
\text { outubro de 2012. }\end{array}$ \\
\hline & $\begin{array}{l}\text { ELIAN, I. T. Memórias escolares } \\
\text { dos sujeitos LGBTT: a escola } \\
\text { como mediadora das } \\
\text { identidades sexuais e de gênero } \\
\text { (UEMG). }\end{array}$ & BUTLER, J. & $\begin{array}{l}\text { Narrativas escolares a partir } \\
\text { de entrevistas com lésbicas, } \\
\text { gays, bissexuais, travestis e } \\
\text { transexuais. }\end{array}$ \\
\hline & $\begin{array}{l}\text { ALMEIDA, H. S. S. Professoras } \\
\text { trans brasileiras: ressignificações } \\
\text { de gênero e de sexualidades no } \\
\text { contexto escolar (UFU)*. }\end{array}$ & $\begin{array}{l}\text { BUTLER, J. } \\
\text { FOUCAULT, M. } \\
\text { LOURO, G. L. }\end{array}$ & $\begin{array}{l}\text { Análise de documentos. } \\
\text { Entrevistas e questionários } \\
\text { aplicados para doze (12) } \\
\text { professoras trans das cinco } \\
\text { regiões do país realizadas } \\
\text { no XVII ENTAIDS em } \\
\text { Aracajú no ano de } 2010 \text { e } \\
\text { na edição do mesmo } \\
\text { evento realizada em } 2012 \text {. }\end{array}$ \\
\hline & $\begin{array}{l}\text { PRADO, V.M. do. Entre ditos e } \\
\text { não ditos: a marcação social de } \\
\text { diferenças de gênero e } \\
\text { sexualidade por intermédio das } \\
\text { práticas escolares de educação } \\
\text { física (UNESP)*. }\end{array}$ & $\begin{array}{l}\text { BUTLER, J. } \\
\text { FOUCAULT, M. } \\
\text { LOURO, G. L. }\end{array}$ & $\begin{array}{l}\text { Questionários } \\
\text { socioeconômicos. } \\
\text { Elaboração de seis (6) } \\
\text { entrevistas } \\
\text { semiestruturadas com } \\
\text { pessoas homoafetivas, a } \\
\text { partir de suas } \\
\text { rememorações sobre as } \\
\text { aulas de educação física na } \\
\text { Educação Básica. }\end{array}$ \\
\hline
\end{tabular}




\begin{tabular}{|c|c|c|c|}
\hline & $\begin{array}{l}\text { PUCHALSKY, H. A/R/Tografia e } \\
\text { enunciações } \\
\text { hibridizações entre arte, gênero } \\
\text { e sexualidade nas narrativas de } \\
\text { professores de arte (UFPR). }\end{array}$ & $\begin{array}{l}\text { BUTLER, J. } \\
\text { FOUCAULT, M. } \\
\text { LOURO, G. L. }\end{array}$ & $\begin{array}{l}\text { Entrevistas com } \\
\text { professoras e professores } \\
\text { de arte e suas narrativas. }\end{array}$ \\
\hline & $\begin{array}{l}\text { CESPEDES, C. R. Memórias de } \\
\text { infância, relações de gênero e } \\
\text { sexualidade nos significados e } \\
\text { narrativas de professores/as } \\
\text { Rondonópolis - MT (UFMT). }\end{array}$ & $\begin{array}{l}\text { BUTLER, J. } \\
\text { FOUCAULT, M. } \\
\text { JOSSO, M. C. } \\
\text { LOURO, G. L. }\end{array}$ & $\begin{array}{l}\text { História oral com foco na } \\
\text { narrativa (auto) biográfica - } \\
\text { sobre sexualidade e } \\
\text { relações de gênero de suas } \\
\text { vivências infanto-juvenis, } \\
\text { na escola - de dois } \\
\text { professores e duas } \\
\text { professoras que atuam na } \\
\text { Educação Infantil e no } \\
\text { segundo ciclo do Ensino } \\
\text { Fundamental nas escolas } \\
\text { das redes públicas de } \\
\text { ensino estadual e } \\
\text { municipal, } \\
\text { Rondonópolis, } \\
\text { Grosso. }\end{array}$ \\
\hline \multirow{5}{*}{2016} & $\begin{array}{l}\text { RODRIGUES, T. A. Morrer para } \\
\text { nascer } \\
\text { pravesti: } \\
\text { performatividades, } \\
\text { escolaridades e a pedagogia da } \\
\text { intolerância (UFSCar). }\end{array}$ & $\begin{array}{l}\text { BUTLER, J. } \\
\text { FOUCAULT, M. } \\
\text { MALINOWSKY.MISK } \\
\text { OLCI, R. }\end{array}$ & $\begin{array}{l}\text { Etnografia com seis } \\
\text { travestis, quanto a suas } \\
\text { vivências escolares. }\end{array}$ \\
\hline & $\begin{array}{l}\text { LARA, R. B. O que dizem os (as) } \\
\text { Docentes acerca da Diversidade } \\
\text { Sexual na Escola (UFOP). }\end{array}$ & $\begin{array}{l}\text { BUTLER, J. } \\
\text { FOUCAULT, M. } \\
\text { LOURO, G. L. }\end{array}$ & $\begin{array}{ll}\text { Entrevistas } & \text { com } \\
\text { professores(as) do ensino } \\
\text { fundamental. }\end{array}$ \\
\hline & $\begin{array}{l}\text { MARTINS, L. R. Entre ocós, } \\
\text { truques e atraques: a produção } \\
\text { de confetos sobre as } \\
\text { experiências de educadoras } \\
\text { trans do projeto "trans"forma } \\
\text { ação (FUFPI). }\end{array}$ & $\begin{array}{l}\text { BUTLER, J. } \\
\text { FOUCAULT, M. } \\
\text { MISKOLCI, R. }\end{array}$ & $\begin{array}{l}\text { Oficinas sócio-poéticas } \\
\text { entre educadores(as) } \\
\text { transgêneros do município } \\
\text { de Teresina, Pl. }\end{array}$ \\
\hline & $\begin{array}{l}\text { LIMA, V. B. C de. Mentir para si } \\
\text { mesmo é sempre a pior mentira: } \\
\text { a heteronormatividade na } \\
\text { narrativa da trajetória escolar de } \\
\text { mulheres lésbicas e bissexuais } \\
(\text { UERJ). }\end{array}$ & $\begin{array}{l}\text { BUTLER, J. } \\
\text { DERRIDA, J. } \\
\text { FOUCAULT, M. } \\
\text { SCOTT, J. }\end{array}$ & $\begin{array}{l}\text { Entrevistas narrativas com } \\
\text { mulheres lésbicas } \\
\text { bissexuais sobre suas } \\
\text { trajetórias escolares. }\end{array}$ \\
\hline & $\begin{array}{l}\text { OLIVEIRA, A. L. Discursos sobre } \\
\text { corpo, gênero e sexualidade na } \\
\text { educação do colégio de } \\
\text { aplicação da Universidade } \\
\text { Federal de Sergipe (UFSE). }\end{array}$ & $\begin{array}{l}\text { BUTLER, J. } \\
\text { DERRIDA, J. } \\
\text { FOUCAULT, M. } \\
\text { LOURO, J. } \\
\text { SCOTT, J. }\end{array}$ & $\begin{array}{l}\text { Entrevistas realizadas com } \\
\text { sete docentes, uma } \\
\text { psicóloga e cinco discentes } \\
\text { do ensino médio - e análise } \\
\text { de discurso. }\end{array}$ \\
\hline
\end{tabular}

FONTE: Quadro elaborado pelos autores a partir do Banco de Teses e Dissertações da CAPES. 
Os marcos teóricos dos trabalhos analisados apontam os estudos em Foucault (1982), Butler (2015) e Louro (2016) como os textos clássicos mais utilizados. Estes autores superam a abordagem de gênero focada no binarismo da matriz heterossexual que tinha em Simone de Beauvoir sua grande representação. No que se refere às abordagens de currículo, Elizabeth Macêdo é referência. Em se falando de currículo subversivo (a teoria Queer), encontra-se em Louro (2016) uma referência destacada nas dissertações analisadas.

No que diz respeito à metodologia utilizada, a maior parte das pesquisas foi realizada com o uso de entrevistas, demonstrando a preocupação dos pesquisadores com as representações sociais presentes nas narrativas e nas histórias de vida, visto que, como afirma Ferrarotti (2010, p. 44): "Toda a vida humana se revela, até nos seus aspectos menos generalizáveis, como a síntese vertical de uma história social. Todo o comportamento ou ato individual nos parece, até nas formas mais únicas, a síntese horizontal de uma estrutura social". Assim, como geralmente ocorre nas pesquisas qualitativas, as investigações deram grande relevância ao mundo dos significados expressos nos discursos dos entrevistados.

Dentre os trabalhos mapeados, é merecedora de ressalte a pesquisa de Bertuol (2013) realizada na educação infantil. Nela foi descrita a reiteração de ações heteronormativas pelos professores em suas práticas de ensino: enquanto as crianças questionavam estas normas durante as brincadeiras, os educadores discriminavam os comportamentos subversivos de meninas e meninos. Isso reafirma a perpetuação sexista na escola, além do ambiente doméstico. Tal postura nos leva a defender a necessidade de estudos de gênero no contexto da educação infantil.

Ainda que o Brasil seja um país reconhecido como da diversidade cultural e laico, é necessário refletir por que os professores se abstêm dos assuntos polêmicos da sexualidade, das identidades e orientações de gêneros. As dissertações estudadas apontam, também, para esses questionamentos, principalmente em se tratando de crianças.

Rodrigues (2016) aponta a resistência de pessoas travestis aos dispositivos do heterosexismo durante suas vivências em tempos de escola. A violência simbólica foi deflagrada por apelidos machistas vindos de alunos e professores. As vítimas eram culpabilizadas pelo corpo docente e gestor. Quando havia o marcador de raça - no caso de duas participantes negras - as violências se intensificavam.

No mesmo enfoque, Lima (2016) discute os sentidos da heteronormatividade prevalente na educação escolar a partir das enunciações de mulheres lésbicas e bissexuais a respeito de suas trajetórias escolares construídas em narrativas. Assim, a vivência escolar tende a ser um processo menos opressivo quando os discursos afirmados no espaçotempo da escola são o de valorização da diversidade.

Martins (2016) abordou em sua dissertação a experiência de educadoras transgêneros no município Teresina-PI. Estas educadoras projetaram, na pesquisa, os seus saberes e experiências educativas, desestabilizando e subvertendo em seus espaços escolares.

Para Foucault (1982), o combate à discriminação por orientação sexual e de gênero supera a ideia de que existe uma verdade sobre o sexo. Nesta conjuntura, a abordagem da heteronormatividade na educação básica é percebida como uma estratégia de questionamento, subversão e superação das opressões e violências às 
pessoas não heterossexuais. Os trabalhos analisados evidenciam, na diversidade sexual, que "novas" sexualidades se tornam inteligíveis e aceitáveis principalmente no espaço escolar, onde devem ser discutidas por todos os atores. Isso proporciona o reconhecimento e acesso aos direitos das pessoas marginalizadas ou consideradas abjetas.

Entendemos, a partir de Freire (2016), que o ensino precisa estar conectado com a necessidade contemporânea de discussão, reflexão e transformações. Ninguém consegue ser se não estiver com os outros. Esta é uma argumentação plausível no decorrer da formação humana. Ademais, o ensino requer a consciência do inacabamento. Por isso, entendemos que, mesmo sob as normas sexistas, homens e mulheres, embora condicionados, não são determinados a renegar suas identidades e sexualidades em prol do engessamento heteronormativo, reiterado no ensino.

Acreditamos, pois, no inédito viável, citado por Freire (2015). A história nos mostrou as subversões da ordem normativa com outras denominações. Mesmo assim, instalaram-se novos paradigmas, práticas inovadoras e mudanças contextuais. Por outro lado, Freire (2016) também alerta para o respeito não somente ao "novo". Para transformar um contexto - onde constam o tradicional, o normativo e o subversivo precisa-se da compreensão de que esses elementos se completam. Esta é uma realidade da qual não se pode evitar. Ademais, a própria consciência ética inspira o respeito ético às diversidades.

\section{CONSIDERAÇÕES FINAIS}

A heteronormatividade atravessa o dispositivo da sexualidade e se reatualiza por meio da suposição de heterossexualidade, na marcação dos sujeitos que dissidiam da norma, pela reafirmação de categorizações em padrões binários de sexualidade e gênero e pela domesticação da diversidade. A ética e a humanidade, porém, fazem pensar além do que está posto. Para isso, é necessário que entre os saberes exista divergências, embora respeitem-se as particularidades da condição humana.

Percebendo, pois, o sexo como performático, é possível edificar práticas de ensino que problematizem os padrões impostos nos papeis sexuais, subvertendo as iniquidades das relações escolares entre os gêneros aceitos e os abjetos. Para tal, há de se remover os antolhos impostos pelas normas do heterosexismo.

Por outro lado, as leituras clássicas desde o fim dos anos de 1990 atentam para a existência latente das normatizações heterossexuais reiteradas nas relações homoafetivas. Talvez sejam necessárias produções com esta problematização. Outro aspecto que merece visibilidade é o das pessoas intersexo, visto que também recebem as insolações das normas sexistas.

No necessário posicionamento das temáticas de gênero, é essencial não atuarmos com neutralidade. Essa é inatingível à lógica de sermos e existirmos. Até mesmo o silêncio projeta uma consequência ou favorece uma situação. É pertinente questionarmos sobre o que nosso campo disciplinar defende, quais conceitos e práticas que o compõem, e em nome de qual condição estamos defendendo saberes, e os corporificando em nossos ditos e feitos. 
MELO, K. M. T.; SOUZA, F. C. S.; PONTES, V. M. A.

Em face às pluralidades existentes e necessárias no universo escolar, a problematização e combate à heteronormatividade pelo ensino das temáticas de gênero precisa ser contextual às demandas existentes e inesperadas que acontecem no movimento do ambiente, na emergência das polêmicas, nos atos hostis e no combate às práticas de homofobia. Trabalhar as temáticas de gênero, como identidade e orientações de gênero, sexualidade e diversidade sexual é uma atitude ética e legítima, visto o necessário combate aos crimes de homofobia no Brasil, assim como a pertinência e atualidade do assunto cada vez mais presente em nosso contexto.

Promover momentos de abordagem, discussão, reflexão e subversão das normas de gênero promove o respeito às diversidades, o combate à homofobia e a plenitude da condição humana. Ademais, a realidade é diversa e igualmente composta por pessoas diversas em suas identidades e orientações de gênero.

Artigo recebido em: 25/08/2017 Aprovado para publicação em: 08/12/2017

HETERONORMATIVITY AND EDUCATION IN BASIC EDUCATION: A STATE OF KNOWLEDGE

ABSTRACT: In this descriptive and qualitative study, we analyzed sixteen works on Banco de Teses e Dissertações da Capes, available through Plataforma Sucupira that meet the topic of heteronormativity on basic education. heteronormativity on basic education Brazil has the highest number of crimes of homotransphobia in the world. The overcoming of this reality seems to go toward the respect ofgender diversity, still fragile on teaching practices, especially in children's education. Even with the suppression of cross-cutting topics about sexual diversity in curricula, we believe that setbacks and advances are into the dynamic of relations between learning and teaching, and have the unprecedented respect and empowerment of gender diversity as a result.

KEYWORDS: Heteronormativity. Gender. Basic education. Sexual diversity.

\section{HETERONORMATIVIDAD Y ENSEÑANZA EN LA EDUCACIÓN BÁSICA: UN ESTADO DEL CONOCIMIENTO}

RESUMEN: En este estudio descriptivo y cualitativo, analizamos diesesseis trabajos realizados por el Banco de tesis y las disertaciones de CAPES accesibles en la Plataforma Sucupira que atendían a la temática de la heteronormatividad en la educación básica. En Brasil se concentra el mayor número de crímenes de homotransfobia del mundo. La superación de esta realidad apunta hacia el respeto a la diversidad de género, todavía frágiles en las prácticas de enseñanza, principalmente en la educación infantil. Aún con la supresión de los temas transversales sobre diversidad sexual em los currículos, acreditamos que los retrocesos y los progresos son constitutivos de la dinâmica de las relaciones de enseñanza y aprendizaje, resultando en la emancipación de las diferencias de género.

PALABRAS CLAVE: Heteronormatividad. Género. Educación básica. Diversidad sexual. 


\section{REFERÊNCIAS}

AYER, F; BOTTREL, F. Brasil é país que mais mata travestis e transexuais. Estado de Minas. Belo Horizonte, 09 mar. 2017. Disponível em:

<http://www.em.com.br/app/noticia/especiais/dandara/2017/03/09/noticia-especialdandara,852965/brasil-e-pais-que-mais-mata-travestis-e-transexuais.shtml>. Acesso em: 02 jul. 2017.

BEAUVOIR, S. O segundo sexo:fatos e mitos. 3. ed., v. 1, Rio de Janeiro: Nova Fronteira, 2016.

BOURDIEU, P. de. A dominação masculina. 2. ed. Rio de Janeiro: Bertrand Brasil, 2002.

BRASIL, Ministério da saúde. Política Nacional de saúde integral de lésbicas, gays, bissexuais, travestis e transexuais. Brasília: Ministério da saúde, 2013.

BUTLER, J. Problemas de gênero: feminino e subversão da identidade. 8. ed. Rio de janeiro: Civilização Brasileira, 2015.

CANCIAN, N. Retirada de "identidade de gênero" do currículo é criticada por entidades. Folha de São Paulo. Brasília, 07 abr. 2017. Disponível em: $<$ http://www1.folha.uol.com.br/educacao/2017/04/1873735-retirada-de-identidade-degenero-do-curriculo-e-criticada-por-entidades.shtml> Acesso em: 02 jul. 2017.

CARRARA, S. Educação, diferenças, diversidade e desigualdade. In: BRASIL. Secretaria de Políticas para mulheres. Gênero e diversidade na escola: formação de professoras/es em gênero, orientação sexual e Relações Étnico-Raciais. Rio de Janeiro: CPESC; Brasília: SPM, 2009.

FERRAROTTI, F. Sobre a autonomia do método biográfico. In: NÓVOA, A.; FINGER, M. (Orgs.). O método (auto)biográfico e a formação. Natal: EDUFRN; São Paulo: Paulus, 2010. p. 31-57.

FERREIRA, N. S. de A. As pesquisas denominadas "estado da arte". Educação \& Sociedade, São Paulo, v. 23, n. 79. p. 257 - 272, ago. 2002.

FOUCAULT, M. Herculine Barbin: o diário de um hermafrodita. Rio de Janeiro: Francisco Alves, 1982.

FREIRE, P. Pedagogia da esperança. Um reencontro com a pedagogia do oprimido. 22. ed. Rio de Janeiro: Paz e Terra, 2015.

FREIRE, P. Pedagogia da autonomia: saberes necessários à prática educativa. 53 ed. Rio de Janeiro: Paz e Terra, 2016. 
MELO, K. M. T.; SOUZA, F. C. S. PONTES, V. M. A.

JUNQUEIRA, R. D. Homofobia na escola: um problema de todos. In: JUNQUEIRA, R. D (Org.). Diversidade sexual na educação: problematizações sobre a homofobia nas escolas. Brasília: Ministério da Educação, Secretaria de Educação continuada, Alfabetização e Diversidade, UNESCO, 2009. p. 13 - 42.

KARNAL, L. Todos contra todos: o ódio nosso de cada dia. Rio de janeiro: Leya, 2017.

L.G.B.TProfissão repórter. Rio de Janeiro: Rede Globo, 26 de abril de 2017. Programa de TV. Disponível em: <http://g1.globo.com/profissao-

reporter/videos/t/integras/v/profissao-reporter-lgbt-26042017/5829216/>. Acesso em 28 abr. 2017.

LIBÂNEO, J. C. Didática. São Paulo: Cortez, 2013.

LOURO, G. L. Pedagogias da sexualidade. In: LOURO, G. L. (Org.). O corpo educado: Pedagogias da sexualidade. 2 ed. Belo Horizonte: Autêntica, 2000. p. 4-22.

. Heteronormatividade e homofobia. In: JUNQUEIRA, R. D (Org.). Diversidade sexual na educação: problematizações sobre a homofobia nas escolas. Brasília: Ministério da Educação, Secretaria de Educação continuada, Alfabetização e Diversidade, UNESCO, 2009. p. 84-119.

Um corpo estranho. Ensaios sobre sexualidade e teoria queer. Belo Horizonte: Autêntica, 2016.

MORIN, E. A cabeça bem-feita:repensar a reforma, reformar o Pensamento. 8. ed. Rio de Janeiro: Bertrand Brasil, 2003.

NOGUEIRA, S. N. B; AQUINO, T. A.; CABRAL, E. A. Dossiê:a geografia dos corpos das pessoas trans. Brasil: Rede Trans Brasil, 2017.

MENINO morre em sala de aula durante sessão de bullying homofóbico. Pragmatismo político, 08 jul. 2016. Disponível em: <https://www.pragmatismopolitico.com.br/2016/07/meninomorre-em-sala-de-aula-durante-sessao-de-bullying-homofobico.html> Acesso em: 10 maio 2017.

ROMANOWSKI, J. P.; ENS, R. T. As pesquisas denominadas do tipo "estado da arte" em educação. Diálogo Educacional, Curitiba, v. 6, n. 19, p. 37 - 50, set./dez. 2006.

SCOTT, J. Gênero: uma categoria útil de análise histórica. New York: Columbia University Press, 1989.

STERLING, A. F. Os cinco sexos: porque macho e fêmea não são o bastante. The Sciences, March/April 1993, p. 20-24. 
UNESCO. O perfil do Professor Brasileiro: o que fazem, o que pensam, o que almejam. Pesquisa Nacional UNESCO. São Paulo: Moderna, 2004.

Katamara Medeiros de Tavares Melo: Bacharel e licenciada em Enfermagem (UERN).

Professora do Curso de Enfermagem da UERN e mestranda em ensino (UERN/IFRN/UFERSA).

E-mail: katavares2010@hotmail.com

Francisco das Chagas Silva Souza: Doutor em Educação (UFRN) e professor do Instituto Federal de Educação, Ciência e Tecnologia do Rio Grande do Norte, Campus Mossoró. Professor do Programa de Pós-graduação em Ensino (UERN/IFRN/UFERSA) e - Programa de Pós-graduação em Educação Profissional e Tecnológica (Mestrado Profissional em Rede).

E-mail: chagas.souza@ifrn.edu.br

Verônica Maria de Araújo Pontes: Doutora em Educação. Professora do Programa de Pós-graduação em Ensino (UERN/IFRN/UFERSA).

E-mail: veronicauern@gmail.com 